\title{
BMJ Open Facilitators and barriers to implement the family doctor contracting services in China: findings from a qualitative study
}

\author{
Shasha Yuan (D) , Fang Wang, Xi Li, Meng Jia, Miaomiao Tian
}

To cite: Yuan S, Wang F, Li X, et al. Facilitators and barriers to implement the family doctor contracting services in China: findings from a qualitative study. BMJ Open 2019;9:e032444. doi:10.1136/ bmjopen-2019-032444

- Prepublication history and additional material for this paper are available online. To view these files, please visit the journal online (http://dx.doi. org/10.1136/bmjopen-2019032444).

Received 19 June 2019 Revised 28 August 2019 Accepted 24 September 2019

Check for updates

(C) Author(s) (or their employer(s)) 2019. Re-use permitted under CC BY-NC. No commercial re-use. See rights and permissions. Published by BMJ.

Centre for Health System and Policy, Institute of Medical Information \& Library, Chinese Academy of Medical Sciences \& Peking Union Medical College, Beijing, China

Correspondence to Professor Fang Wang; wang.fang@imicams.ac.cn; 359959291@qq.com

\section{ABSTRACT}

Objective To identify the facilitators and barriers to implement family doctor contracting services in China by using Consolidated Framework for Implementation Research (CFIR) to shed new light on establishing family doctor systems in developing countries.

Design A qualitative study conducted from June to August 2017 using semistructured interview guides for focus group discussions (FGDs) and individual interviews. CFIR was used to guide data coding, data analysis and reporting of findings.

Setting 19 primary health institutions in nine provinces purposively selected from the eastern, middle and western areas of China.

Participants From the nine sampled provinces in China, 62 policy makers from health related departments at the province, city and county/district levels participated in 9 FGDs; 19 leaders of primary health institutions participated in individual interviews; and 48 family doctor team members participated in 15 FGDs.

Results Based on CFIR constructs, notable facilitators included national reform involving both top-down and bottom-up policy making (Intervention); support from essential public health funds, fiscal subsidies and health insurance (Outer setting); extra performance-based payments for family doctor teams based on evaluation (Inner setting); and positive engagement of health administrators (Process). Notable barriers included a lack of essential matching mechanisms at national level (Intervention); distrust in the quality of primary care, a lack of government subsidies and health insurance reimbursement and performance ceiling policy (Outer setting); the low competency of family doctors and weak influence of evaluations on performance-based salary (Inner setting); and misunderstandings about family doctor contracting services (Process).

Conclusions The national design with essential features including financing, incentive mechanisms and multidepartment cooperation, was vital for implementing family doctor contracting services in China. More attention should be paid to the quality of primary care and competency of family doctors. All stakeholders must be informed, be involved and participate before and during the process.

\section{INTRODUCTION}

A well-implemented family doctor system has been shown to be positively related to better health outcomes and healthcare cost

\section{Strengths and limitations of this study}

This is the first qualitative study to systematically examine the factors influencing the implementation of the family doctor contracting services in China.

- The Consolidated Framework for Implementation Research (CFIR) was used to guide data coding, data analysis and reporting of findings.

- Different stakeholders from the policy making level to the policy implementation level from nine provinces of China were involved to make the qualitative data more comprehensive.

- Demand-side perspectives should be included in future research, as they are necessary for people-centred health systems.

- The original interview guides were not precisely informed by the CFIR, with the possibility for missing information under some CFIR constructs.

containment in practice. ${ }^{12}$ Family doctors are medical specialists trained to provide primary and continuing care for all individuals regardless of age, sex or type of health problems, and coordinate comprehensive healthcare services with other specialists as needed. ${ }^{3}$ Family doctors may also be known as family physicians or general practitioners in some countries. Their education includes a greater emphasis on public and community health. Due to these qualities, family doctors play a valuable role in the primary care system, and the 'gate-keeping' role of family doctors has been accepted by many governments globally. 45

In China, there is a shortage of well-trained and qualified general practitioners, particularly in rural areas. Therefore, in the new round of healthcare reform beginning in 2009 , it has been particularly prioritised to establish a sound education and training system to improve both the number and competencies of general practitioners in primary care. Generally, there are two current models for general practitioners' training and education in China. ${ }^{67}$ The first model is an on-the-job training programme that was 
started in 2000 and that normally lasts for 12 months. It targets the majority of the less-educated physicians who currently work in local township health centres (THCs) or community health centres (CHCs) and aims to transform them into qualified general practitioners. ${ }^{8}$ The entire training schedule includes 1 month of theoretical study of basic sciences and general practice, followed by 10-month primary rotational blocks in teaching hospitals and 1 month practice-based training in the community. ${ }^{8}$ The second model is a 3-year general practice postgraduate residency training programme that was initiated in August 2011 by the Chinese government. It aims to develop the professional competence of physicians who wish to practice in the specialty of general practice after 5 years of study at a medical university. ${ }^{67}$ A typical training programme consists of 3 months of theoretical study on general practice, followed by a 26 -month clinical rotation and expertise training and a 7-month community-based health service practice. ${ }^{9}$ Currently, approximately $50 \%$ of registered general practitioners in the primary care system were trained according to the first model,${ }^{10}$ which has been regarded as one of the most efficient ways to solve the shortage of general practitioners in China.

Furthermore, the primary care system in China has faced substantial challenges during market-based reforms since the 1980s, including inadequate government funding, poor quality of care and shortages in the skilled workforce. ${ }^{11-13}$ In this context, the gatekeeping function of family doctors in China has been extremely lacking and patients have been used to visiting hospitals directly, which has contributed to hospital overcrowding and cost increases. Therefore, establishing and strengthening family doctor system in China became one of the most important issues in the 2009 healthcare reform. Afterwards, several key documents were released to emphasise the gatekeeping role of family doctors based on the characteristic of first contact in primary care. In June 2016, based on pilot experiences of local governments, seven related departments jointly issued a policy about implementing the family doctor contracting services in China, which was regarded as an official indicator of the establishment of the family doctor system nationally. To achieve quick coverage, the quantitative contracting rate goal was clearly set at $30 \%$ for the total population and $60 \%$ for target groups such as the elderly population and children and residents with common chronic diseases, by the end of 2017. In the meantime, this reform was regarded as the initial stage of the family doctor system in China, which would be called the 'family doctor contracting services' due to a lack of several essential uniform features such as health insurance support, appropriate incentive mechanisms and objective evaluation methods, which represented a difference from international experiences.

Establishing a well-implemented family doctor system is believed to be very complex and time-consuming. Thus, identifying the facilitators and barriers to implement the reform in the initial stage is an important way to guide the development of efficient strategies. Recent research related to the family doctor contracting services has mostly been published in Chinese and has focused on policy content analysis, ${ }^{14}$ qualitative and quantitative assessments by contracted residents, ${ }^{15}{ }^{16}$ coordination mechanism with health insurance ${ }^{17}$ and the current situation in specific areas. ${ }^{18} 19$ The conclusions drawn from these previous studies, however, were usually based on experiences in specific areas or related to aspects of the reform. To the best of our knowledge, comprehensive analysis of the reform, such as on viewpoints of different stakeholders to explore factors influencing the reform based on nationally represented experiences, has rarely been conducted. Moreover, considering the lack of evidence about family doctor systems in developing countries, the pilot experience of China, as the largest one in the world, would provide more useful and practical evidence for countries with similar contexts than the knowledge produced by developed countries. Therefore, it is meaningful to disseminate such evidence from China internationally. Unfortunately, only two studies published internationally have targeted the ongoing family doctor contracting services reform, and they were both quantitative based on data from Shanghai to analyse residents' contracting behaviour. ${ }^{40}$ More qualitative studies, particularly concerning the facilitating and inhibiting factors of the reform in China are needed to enrich the international evidence.

The goals of our study were to identify the facilitators and barriers to implement the family doctor contracting services in China by using the Consolidated Framework for Implementation Research (CFIR) and to provide policy implications to shed new light on establishing family doctor systems in developing countries. Particularly, it was expected that the factors related to policy and incentives in both the outer and inner settings, and the engaging and executing processes would be important during the initial stage of the implementation of the family doctor contracting services in China.

\section{METHODS}

\section{Design and study team}

Because our research question is descriptive and exploratory, we adopted a qualitative research design involving both focus group discussions (FGDs) and individual interviews. Five researchers from the Institute of Medical Information designed and conducted the study, and all of them had expertise in relevant areas (FW, professor, $\mathrm{PhD}$, over 25 years of experience in primary healthcare with expertise in qualitative study design; $\mathrm{SY}$, associate professor, $\mathrm{PhD}, 10$ years of experience in health policy and the design and implementation of qualitative research and data analysis; MT, associate professor, $\mathrm{PhD}, 10$ years of experience in health policy and the implementation of qualitative research and data analysis; MJ, assistant researcher, $\mathrm{PhD}, 6$ years of experience in qualitative data collection and analysis; and $\mathrm{XL}$, assistant researcher, $\mathrm{PhD}, 6$ years of experience in 
qualitative data collection and analysis). Four master's students with public health and health policy backgrounds were also involved in the study, writing filed notes and transcribing and processing data. The standards for reporting qualitative research guidelines were used (see additional file 1 ). ${ }^{21}$

\section{Study setting and participants}

Considering the national implementation of the family doctor contracting services reform in China, three provinces in each area of China were purposively selected by considering the economic status, demographic characteristics and basis for health reform: Zhejiang, Jiangsu and Fujian in the eastern area; Shanxi, Hubei and Anhui in the middle area; and Qinghai, Sichuan and Chongqing in the western area. Then, 19 primary health institutions from the sampled provinces including 12 CHCs and 7 THCs were purposively selected to collect qualitative data at the bottom level. Generally, primary health institutions with special contracting services for targeted groups such as children (0 6 years), the elderly population (above 65 years) and patients with chronic diseases (eg, hypertension, diabetes, tuberculosis and serious mental disorder) were prioritised. We included both CHCs in urban areas and THCs in rural areas. In addition, we also considered the size (represented by the number of health technicians) and total visits of the primary health institutions to maximise the heterogeneity as much as possible. The number of health technicians among the selected primary health institutions ranged from 19 to 171 in 2016 while the number of total visits of them ranged from 4806 to 366563 in 2016. Last, to obtain a full understanding of the implementation of the family doctor contracting services in China, the stakeholders from the administrative level in charge of policy making (including directors or chief executives of departments related to health, health insurance and human resources) to the bottom level responsible for policy implementation (including the leaders of primary health institutions and family doctor teams) were purposively selected.

In particular, FGDs were used to interview policy makers and family doctor teams while individual interviews were used to interview the leaders of CHCs and THCs. In practice, the leaders of the primary health institutions played vital roles in connecting policy makers at upper levels with policy practitioners at the bottom level. They were usually responsible for processing policy information first and then designing the specific implementation plans and supervising and evaluating the performance of family doctor teams. Therefore, it was more suitable to conduct individual interviews with the leaders of the primary health institutions. In total, 62 policy makers in the related departments at different levels participated in 9 FGDs, 19 leaders of primary health institutions (CHCs/ THCs) participated in individual interviews and 48 family doctor team members participated in 15 FGDs, as shown in table 1.
Table 1 Information on the FGDs and individual interviews by study site

\begin{tabular}{lllll}
\hline & & $\begin{array}{l}\text { FGDs- } \\
\text { policy } \\
\text { makers } \\
\text { (size) }\end{array}$ & $\begin{array}{l}\text { Individual } \\
\text { interviews- } \\
\text { leaders } \\
\text { of CHCs/ } \\
\text { THCs }\end{array}$ & $\begin{array}{l}\text { FGDs- } \\
\text { family } \\
\text { doctor } \\
\text { teams } \\
\text { (size) }\end{array}$ \\
\hline Eastern & Zhejiang & $1(6)$ & 2 & $1(4)$ \\
area & Jiangsu & $1(8)$ & 3 & $2(3 / 3)$ \\
& Fujian & $1(6)$ & 2 & $2(3 / 3)$ \\
Middle area & Shanxi & $1(6)$ & 1 & $1(4)$ \\
& Hubei & $1(6)$ & 1 & $1(4)$ \\
& Anhui & $1(8)$ & 2 & $2(3 / 3)$ \\
Western & Qinghai & $1(8)$ & 3 & $2(3 / 3)$ \\
area & Sichuang & $1(8)$ & 3 & $2(3 / 3)$ \\
& Chongqing & $1(6)$ & 2 & $15(48)$ \\
\hline In total & & $9(62)$ & 19 &
\end{tabular}

$\mathrm{CHC}$, community health centre; FGD, focus group discussion;

THC, township health centre.

\section{Data collection and reflexivity}

The interviews were conducted in Chinese from June to August 2017. The interview guides were developed with the aim of understanding the implementation of the family doctor contracting services reform, including key themes with several specific questions: (1) Reform initiation, such as the reform basis, multidepartment cooperation and the characteristics of family doctors. (2) The specific contents of the reform implementation, such as the constitution of family doctor teams, service package design and incentive mechanisms. (3) Challenges and future plans. The interview guides were tailored for the category of respondents.

With the agreement of the interviewees, we digitally audio recorded all of the questions and answers. In each province, three categories of respondents were interviewed to ensure the inclusion of views from different interest groups in the reform. Specifically, one FGD was conducted with administrators working at each level, that is, province, city and district/county levels of the departments of health, health insurance and human resources to obtain information from the perspectives of health policy makers at different levels; each FGD lasted approximately $90 \mathrm{~min}$. Then, one to three individual interviews were conducted with the leaders of the selected CHCs and THCs, which lasted approximately $60 \mathrm{~min}$ and one or two FGDs were also conducted with family doctor teams, which lasted 60-90 min to obtain information from the practitioners directly responsible for the reform. Respondents were recruited until theoretical saturation was achieved. ${ }^{22}$

\section{Data analysis}

The digital recordings were transcribed by four master's students in health policy and public health and 
cross-examined by the researchers conducting the interviews. CFIR was used to guide data coding, data analysis and reporting of the findings. CFIR is a conceptual framework that was developed to guide the systematic assessment of multilevel implementation contexts to identify factors that might influence intervention implementation, and help produce findings to inform policy makers on improvements in priority areas. ${ }^{23}$ Barriers and facilitators are categorised into 39 constructs under five critical domains: Intervention characteristics, Outer setting, Inner setting, Characteristics of the individual and Process (see additional file 2). CFIR is intended to be flexible in application so that researchers can tailor the framework to the specific intervention design, factors and context being studied. CFIR has been cited in more than 300 published articles since its publication in 2009. ${ }^{24}{ }^{25}$

A codebook was developed based on the CFIR constructs, and additional codes that emerged from the transcripts were added when possible. MAXQDA2018 (VERBI Software GmbH, Bismarckstraße 10-12, 10625 Berlin, Germany) was used to process, and code the data. Three researchers (SY, XL and MJ) participated in refining the codebook by coding one transcript in each area. Once consensus was achieved, the three researchers above coded the transcripts independently with discrepancies resolved through discussion (with FW and MT). To adapt the CFIR to our study, we removed the CFIR codes that were not reflected in the transcripts and merged the minor themes. In detail, we described Intervention characteristics in general without detailed constructs; removed Cosmopolitanism and added Information system from Outer setting domain; removed Networks and communications, part of Implementation climate (keeping the contents of Organisational incentives and rewards and Goals and feedback), and Readiness for implementation from the Inner setting domain; removed the Characteristics of individuals domain; and in the Process domain, merged Engaging and Executing into one construct, and merged Reflecting and evaluating and Goals and feedback into one construct due to the overlap of the information in practice. In addition to our narrative report on these findings, we developed a summary table of the factors influencing the implementation organised by the CFIR domains to visualise them in this manner.

\section{Patient and public involvement}

No patients or public were involved in the data analysis. The participants were not invited to contribute to the analysis or writing of the paper; they were only invited to participate in the interviews.

\section{RESULTS}

Tables 2 and 3 summarise the facilitators, barriers and factors with mixed influences that were identified during the implementation of the family doctor contracting services in China based on the CFIR domains. In particular, the following constructs with the most content were selected to describe in detail how these factors influenced the reform implementation: Intervention characteristics; Patient needs, Peer pressure, External policy and incentives and Information systems in the Outer setting domain; Organisational incentives and rewards and Goals and feedback in the Inner setting domain; and Engaging and Executing in the Process domain.

\section{Intervention characteristics}

The implementation of the family doctor contracting services in China involved a combination of both top-down and bottom-up process. On the one hand, the National Health Commission designed basic rules such as on service packaging, possible financing channels and incentive mechanisms as guiding advice, and specific contents were piloted by local governments according to the local context and needs. On the other hand, the best practices tried by local governments were probably influenced the decision of the national government and were recommended for other places as the typical models.

The complexity of the family doctor contracting service in China was also anticipated at the starting point. The establishment of the essential matching mechanisms to guarantee the development of the family doctor system have always been lacked, which was time-consuming and was usually based on national policy or law informed by international experience rather than local piloting in China. Cooperation among multidepartments, such as the National Health Commission; Ministry of Human Resources and Social Security; Ministry of Finance, is also very challenging in China. The difficulty of such cooperation was reflected in the following quote: It is too hard to negotiate with different departments beyond health. The work could be finished only when the issues were clearly stated in the national policy which was actually always lacking in this stage' (respondent in the FGD with policy makers).

\section{Outer setting}

\section{Patient needs}

The severe challenge of the growing elderly population was a facilitator that advances the implementation of the family doctor contracting services. The health administrators in Hangzhou, which has experienced rapid population ageing, stated, 'The elderly population above 65 years old will increase very quickly in the next 5 years, which has introduced big challenges for our primary care system. It is a good time now to establish family doctor system in China with the start of the contracting services. We could think more about the integration of primary care and elderly care accompanying this reform?

It was believed that patients actually have a great need for this reform but that there is a substantial amount of misunderstanding about 'family doctors'; as one respondent stated, 'The family doctor should visit me at home whenever needed' (respondent in the FGD with family doctor teams). This misunderstanding was predicted as one of the main barriers to implement family doctor contracting service in China. 
Table 2 Facilitators and barriers influencing the family doctor contracting services reform

\begin{tabular}{lll}
\hline CFIR domain and constructs & Facilitators & Barriers \\
\hline Intervention characteristics & National reform based on pilot & Lack of essential matching \\
& experience & mechanisms at the national level \\
& Combination of both top-down and & \\
& bottom-up policy making progress &
\end{tabular}

Outer setting

\begin{tabular}{|c|c|c|}
\hline Patient needs and resources & $\begin{array}{l}\text { Increasing growing elderly population } \\
\text { that makes the reform more necessary }\end{array}$ & $\begin{array}{l}\text { Distrust in quality of primary care } \\
\text { Misunderstandings about family } \\
\text { doctors }\end{array}$ \\
\hline External policy and incentives & $\begin{array}{l}\text { Support of essential public health } \\
\text { funds, fiscal subsidies and health } \\
\text { insurance } \\
\text { Supportive health insurance policies } \\
\text { Non-financial incentives including } \\
\text { title promotion, overseas training } \\
\text { opportunities and honorary rewards }\end{array}$ & $\begin{array}{l}\text { Lack of fiscal subsidies and health } \\
\text { insurance reimbursement } \\
\text { Ceiling policy for performance-based } \\
\text { income }\end{array}$ \\
\hline Information system & $\begin{array}{l}\text { Apps developed specifically for family } \\
\text { doctor contracting services } \\
\text { Uniform health information system }\end{array}$ & $\begin{array}{l}\text { Fragmentation of the health } \\
\text { information system }\end{array}$ \\
\hline
\end{tabular}

Inner setting

\section{Structural characteristics}

.

\section{Culture}

Organisational Incentives and
rewards

Organisatic
rewards

Goals and feedback/reflecting and evaluating the progress
- Emphasis on the role of family doctors by building workrooms named after team leaders

- Formation of their own characteristics, such as Chinese traditional medicine and chronic disease management, and slogan

- Additional income to reward family doctor teams for better performance

- More opportunities for career development for excellent family doctors

- Specific evaluation methods to supervise implementation at different levels

- Evaluation results closely related to performance-based salaries

- Timely dissemination of conclusions on best practice
- Low competency of family doctors

- Lack of family doctors with higher education, senior titles and younger age age

r

- No extra payments for family doctor teams with better performance
- Little influence of evaluation results on performance-based salaries

\section{Process}

Engaging and executing
- Positive engagement of health administrators in the reform

- More training about the reform to become a qualified family doctor

- Clear responsibility for family doctor team members

- Positive involvement of rural residents
Misunderstandings about the family doctor contracting services

- Negative involvement of urban residents

Note: The factors in bold were frequently mentioned by the respondents.

CFIR, Consolidated Framework for Implementation Research.

Peer pressure

The local governments routinely summarised their best practices in policy briefs and submitted them to the National Health Commission, which disseminated selected successful strategies nationally and called them 'certain models', such as the 'Shanghai Changning 


\begin{tabular}{|c|c|c|}
\hline CFIR constructs & Mixed factors & Influence on the reform \\
\hline \multicolumn{3}{|l|}{ Outer setting } \\
\hline \multicolumn{3}{|l|}{ Process } \\
\hline Planning & $\begin{array}{l}\text { General planning at the national level } \\
\text { with detailed rules required at the } \\
\text { local level }\end{array}$ & $\begin{array}{l}\text { Good for adaptation to the local context but a lack of essential } \\
\text { arrangements at the national level }\end{array}$ \\
\hline
\end{tabular}

CFIR, Consolidated Framework for Implementation Research.

Model', for the recognition and application of local practices. The competitions created peer pressure to stimulate the development of family doctor contracting services but the dissemination lacked a consideration of the different local contexts with unbalanced primary care bases and different support from related departments. The following quote reflected the general attitude of local health officers, especially in the western area: 'We went to several places recommended by National Health Commission like Shanghai, Xiamen, Hangzhou, etc., to learn about their superior experiences in the support of health insurance and incentive mechanisms. However, most moves cannot be adapted to our own context due to the lack of a comparable economic level'.

\section{External policy and incentives}

The financing policy for the family doctor contracting service was regarded as one of the most important contributors to implementing the reform. The national policy required that the financing should be from health insurance funds, essential public health funds and contracted residents, but without a specific amount or proportion for each part. In practice, health insurance support was represented by providing policy benefits to contracted residents, such as waived or decreased deductibles, and continuous deductible calculations among different levels of hospitals for reimbursement. The situation differentiated greatly among locals, as the reimbursements for the family doctor contracting services in minority areas reached $¥ 120$ per person per year, which greatly stimulated CHCs and THCs to implement the reform more efficiently. However, in majority areas, health insurance denied the reimbursement of contracting services provided directly by family doctors but still provided reimbursement to the patients for direct visits to hospitals. This common situation was reflected in the following quotes by a provincial health administrator, 'Sometimes, the officers in the health insurance bureau would say that primary health institutions had already been reimbursed for the medical services they provided. It was not reasonable to be reimbursed by the fund again. It is not clear what kind of services are included in the family doctor contracting services'.

Interestingly, the participants agreed on the use of essential public health funds to support family doctors. The dilemma was that approximately $90 \%$ of the fund was already allocated to primary health institutions without the reform, so little incentives were produced in this way. As stated by one CHC leader, 'There was lots of overlap between the family doctor services and the essential public health service package. Actually, we were not clear about the difference between them?

The incentive mechanism here pointed to the policies outside the area of health, which was different from the findings for the inner setting. The greatest obstacle was the ceiling for performance-based income for the health staff working in public CHCs and THCs, which did not allow extra bonus allocation. The greatly increased workload due to the contracting services for the health staff in primary health organisations was not compensated with corresponding payments independent of the staff's original salary system. Although acknowledging the necessity for financial incentive mechanisms, the participants in the majority of the study areas reported being unable to find a way around the policy. The problem stemmed from the difficulty of cooperation with the Department of Human Resources, who believed that the services provided by family doctors should be already covered by the original income budget. In addition, the local governments also implemented several non-financial incentives, including title promotion, overseas training opportunities and honorary rewards, as facilitators of the reform. For example, two leaders of family doctor teams in Yichang, Hubei, were rewarded with the May first Labour Medal, a relatively high honour for primary care providers, in 2017 for their excellent performance during the implementation of the family doctor contracting services. 


\section{Information system}

The information system construct was new that is not part of the CFIR but was generated from the transcripts. A well-implemented uniform information system helped family doctors obtain complete health information of the contracted residents from different hospitals for highquality health management. This system was also a fundamental basis for remote medical coordination between family doctors and specialists at hospitals. However, a seamless connection between the medical information system and the essential public health system, the two main information systems in the primary health institutions, was only established in five of the nine provinces. The negative influence of the fragmentation of such connections was evidenced by the duplication of work between two systems, leading to the low efficiency of family doctors.

Additionally, apps for family doctor contracting services were also developed to make the services easier and more convenient for residents. Through such apps, the residents could select and find contracting family doctors, search medical information and even make appointments with hospitals if needed in some places.

\section{Inner setting}

Organisational incentives and rewards

Both financial and non-financial incentives within health organisations were observed to stimulate primary care providers to be actively involved in the reform. Notably, the reward policy was always consistent with the principle of the Human Resources Department mentioned in the results on external policy and incentives. In practice, the main revenue that primary health institutions used to reward family doctors was essential public health funds and charges of personnel contracting service packages, which were not uniform but were determined by local health departments in most cases. Additionally, the recognition of excellent family doctors and the family doctor team with the best performance was held every year in all cases. Once selected, the doctors and teams were praised and provided with more opportunities for their career development. For example, pictures of excellent family doctors were placed on the wall to increase the doctors' reputation among residents.

\section{Goals and feedback/reflecting and evaluating the progress}

These two constructs were merged into one construct considering their common characteristics during the implementation of the reform. Based on the national quantitative contracting rate goals of $30 \%$ and $60 \%$, all study areas set their own specific targets and established corresponding evaluations. Almost all respondents reported that the national goal was barely reached or was reached only with the provision of low-quality services, especially in the provinces where the local government increased the contracting rate to a higher level. The attitudes of local health administrators towards the national goal can be summarised in the following quote: 'The goal should be more reasonable, and quality of care should be considered as the first choice, particularly for the initial stage of the family doctor contracting services. We had no idea about the process of setting the two goals. We were evaluated by the quantitative goals; therefore, we must do our best to satisfy them first'.

Following the national goals, the health departments at different levels designed evaluation methods to supervise the implementation of the reform. At the bottom level, CHCs and THCs designed more detailed evaluation methods and assessed the performance of family doctors monthly. A higher proportion of the allocation of performance-based salaries being based on the evaluation results usually resulted in a positive influence on the reform. However, this scenario was not common. The following quote reflected the general attitudes of the family doctor teams towards the evaluation methods: ' $I$ don't think the evaluation of the family doctor contracting service had much influence on my performance-based salary. It only accounted for a very small proportion. I don't care about this small part increasing'.

\section{Process}

\section{Engaging and executing}

The family doctor contracting service was carried out through teams comprised of physicians, nurses, public health workers and other assistants without professional knowledge. Considering the current shortage of general practitioners, family doctors mainly included registered general practitioners (including assistant general practitioners and traditional Chinese medicine physicians) and other qualified physicians working in primary health institutions, which represents a broader range of professionals than that included in the critical standard of 'general practitioner', particularly in rural areas. In particular, family doctors were usually appointed as team leaders responsible for conducting performance evaluations of team members and managing issues. The nurses took charge of normal nursing care and helped family doctors provide medical services. Public health workers mainly provided essential public health services following the national guidelines. Due to a lack of health personnel, the assistants undertook all non-medical issues to relieve physicians and nurses from paperwork, such as entering basic information of residents. Sometimes, a pharmacist was also included on the team. In the context of ongoing integration reform between primary health institutions and hospitals, specialists were also supposed to be team members to increase the attraction of the family doctor team. Therefore, the team size ranged from 4 persons to 10 or more persons in different study areas.

The contracting service package normally covered two categories: the essential public health service package fully subsidised by the government and different kinds of personalised service packages partly paid by the contracted residents. The contracting was voluntary, and the residents were encouraged to sign a contract with family doctors in their neighbourhood. In practice, children covered by the immunisation programme were 
fully funded by the government, and pregnant women registered to primary health institutions and the original target groups for essential public health funds were automatically regarded as being contracted in the initial stage. These groups were provided a contract when seeking health services in person or through the electronic system. Others were contracted when they sought care at primary health institutions or through door-to-door visiting.

Additionally, a discrepancy between rural and urban residents was also found during the implementation. It was much easier to establish contracts and relationships with rural residents than urban residents. This could be explained by the following quote from one CHC leader: 'The medical resources in urban areas were affluent, so the urban residents had more choices. Compared with rural residents, a larger part of urban residents were covered by the urban employee medical insurance. Sometimes, the CHCs were not included in the appointed insurance organisations'. Attracting urban residents to sign contracts was challenging, and the current contracting service package was far from sufficient to meet their demands.

\section{DISCUSSION}

The family doctor contracting service in China made progress in its coverage, as the contracting rate reached $35 \%$ for the total population and $65 \%$ for the target groups by the end of $2017 .{ }^{26}$ This study provides a detailed description of how facilitating and inhibiting factors influence the implementation of the family doctor contracting services by using the CFIR constructs. In particular, three findings are discussed further, and then policy implications for the future development of the family doctor contracting services and insights for developing countries are provided.

First and foremost, the precondition for residents' acknowledgement of the gatekeeping role of family doctors is their trust in the quality of primary care and competency of family doctors. ${ }^{27}$ Unfortunately, residents in China perceive primary healthcare to be of poor quality, as large discrepancies exist between hospital care and primary care. ${ }^{28}$ The average consultation length of primary care physicians in China was reported to be only $2 \mathrm{~min}$, which is far behind that of other countries. ${ }^{29}$ The lack of high-quality training and education systems has greatly contributed to the low quality and quantity of family doctors in China. Data from the China Health Statistics in 2018 revealed that $55.2 \%$ of licensed general practitioners in CHCs (urban areas) and $82.4 \%$ of those in THCs (rural areas) did not hold a bachelor's degree from a medical university. ${ }^{30}$ The majority had received their medical training no more than 5 years after the completion of secondary school, where knowledge and skills of general practice were more or less neglected. In addition, the number of general practitioners per 10000 people was only 1.82 in China in 2017, while it was 14.5 in Australia (2017) and 6.2 in the UK (2015). ${ }^{31}$ Moreover, this number was also unbalanced within China, at 2.42 in the eastern area, 1.46 in the central area and 1.33 in the western area. ${ }^{30}$ These numbers could partly explain the unbalanced implementation of the family doctor contracting services among the study areas. Fortunately, positive steps have already been taken to increase the number of qualified general practitioners. Along with the new healthcare reform in 2009, the Chinese government further strengthened on-the-job training programmes for physicians working in primary health institutions to improve their competency. Meanwhile, a postgraduate residency training programme (also known as the '3year general practice standardised training') was initiated in 2011 to attract new qualified physicians to become family doctors in primary health institutions. ${ }^{9}$ Now this programme is the core element for new medical graduates who wish to engage in community health services in the primary care setting.

However, the lack of an appropriate incentive mechanism for family doctors is still one of the greatest challenges to the implementation of the family doctor contracting services. This study revealed that very large discrepancies existed in the financial and non-financial incentives among different areas, which greatly influenced the performance of family doctors. The discrepancies also hindered physicians who had finished 3-year postgraduate residency training to practice in primary health institutions. ${ }^{32}$ Physicians working in hospitals, particularly at the tertiary level, have higher social respect, receive more opportunities for career development and are better paid. ${ }^{8}$ Therefore, incentive mechanisms are urgently needed in primary care to attract and retain qualified family doctors, especially for those who have obtained a bachelor's degree from a medical university and have completed a 3-year standardised general practice training programme. Supportive policy and guidelines are also necessary to build strong recognition of family doctors. Only when the normalised incentive mechanism is established at the national level can the family doctors contracting service be sustainable.

Second, the family doctor contracting service reform was designed at the national level on the basis of local pilot experiences. The general principles were predetermined based on national policy, including for family doctor teams, financing sources, responsible departments and quantitative goals, which were favourable for the initial stage of reform. However, the disadvantage of low working efficiency also gradually increased with the development of the family doctor contracting services, as its implementation greatly depended on the willingness and negotiation ability of the local government. For example, in practice, multidepartment cooperation was indicated to be a challenging issue, especially at the local level, particularly for negotiation with the Ministry of Human Resources and Social Security, which was commonly reflected by the respondents during the implementation. An important reason for this difficulty was that the national government did not clarify the role of health insurance and described capitation payment 
for family doctors in detail but only noted the need for cooperation among several key departments related to health, finance, human resources and social security. In the long run, it is necessary to establish all the above essential matching mechanisms at the national level in detail to improve the reform efficiency. In comparison, countries with well-performed family doctor systems, such as the UK, ${ }^{33}$ Australia ${ }^{34}$ and Germany, ${ }^{35}$ all emphasise the gatekeeping role of family doctors and health insurance support in the form of laws or regulations with specific details.

Finally, quality-oriented evaluation methods are needed in future implementations. The quantitative goal was set at the initial stage for rapid and wide coverage of the reform in 2017. However, the achievement of the quantitative goal also generated side effects; for example, the service provided by family doctors was relatively of low quality, with little attraction for residents. Moreover, the incentive mechanism was not implemented well, as the evaluation method was not closely related to performance-based payments for family doctors. A suitable evaluation method should provide professional guidance beyond the supervision role through the use of indicators. The Quality and Outcome Framework in the UK is regarded as a good example of a combination of guidance, evaluation and payment. ${ }^{36}$ More efforts should be devoted to this issue in China.

Based on the findings and discussions of this study, future strategies for implementing the family doctor contracting services in China should be considered from two aspects. Specifically, in the short run, the government could continue to encourage piloting by local governments for issues such as the constitution of the family doctor team, personalised contracting service package design, non-financial incentives for family doctors' performance and methods of attracting residents to sign contracts. It is favourable to maintain discrepancies in these issues across the country, as these issues usually rely on local needs and require little cooperation with other departments. In the long run, we still need to strengthen and improve the national design of the family doctor contracting services. Four essential components are particularly worth emphasising: the national training and education system for qualified general practitioners, which serves the basis of the family doctor contracting service; the national incentive mechanism specifying career development and the salary system based on scientific evaluation methods; sustainable funding from the government and health insurance; and the responsibility of key departments.

Furthermore, based on the CFIR framework, several policy implications for developing countries struggling to establish family doctor systems are also outlined. First, for interventions, a national design with detailed and adaptable contents, including financing and incentive mechanisms, should be decided in the form of law or regulation. Second, in the inner setting, more attention should be paid to the quality of primary care and the competency of family doctors. Third, in the outer setting, the national design needs to clarify the role of essential departments. Finally, all stakeholders should be informed, be involved and participate.

This study has three limitations. The first is that the original interview guides were not explicitly informed by the CFIR in order to make them more understandable to the respondents. Thus, it is possible that the constructs that did not emerge with detailed information were simply not addressed in the interviews, such as the characteristics of individuals. However, the comprehensiveness of the CFIR constructs as a tool for examining implementation has been confirmed in many different settings. ${ }^{24}$ Second, the interviews were conducted among health administrators and primary care providers, as they were the major reform practitioners involved in the initial stage. The perspectives of the residents were mainly reflected by family doctors in this study. Demand-side views should be included in the next stage and in future research, as they are necessary for people-centred health systems. The third limitation is that sometimes it was not possible to distinguish factors as facilitators or barriers considering the complexity of the reform and the various local contexts. Hence, these factors were labelled as mixed factors in this study.

In conclusion, our study is the first qualitative study to systematically examine the factors influencing the implementation of the family doctor contracting services in China using CFIR as an organising theoretical framework. These findings help inform policy makers in future efforts to promote the final establishment of the family doctor system in China and provide insights for other developing countries, particularly for those struggling in the initial stage.

Acknowledgements The authors thank the health departments and primary health institutions in Zhejiang, Jiangsu, Fujian, Anhui, Hubei, Shanxi, Sichuan, Chongqing and Qinghai province for their help in data collection. The authors also thank the former National Health and Family Planning Commission for their support particularly for coordination with study sites. The authors also thank the faculty members and postgraduates from the Institute of Medical Information and Library for their work in data collection.

Contributors SY collected, processed and analysed the data, and wrote and finalised the manuscript. FW designed the study and provided advice on the analysis framework. XL, MJ and MT actively participated in data collection and analysis, and modification of the paper. All authors read and approved the final manuscript.

Funding This work was supported by CAMS Innovation Fund for Medical Sciences (CIFMS) [2016-I2M-3-018].

Competing interests None declared.

Patient consent for publication Not required.

Ethics approval This study was approved by the Institute of Medical Information \& Library Human Research Ethics Committee (HREC) (Ref. No. IMICAMS/03/19/HREC).

Provenance and peer review Not commissioned; externally peer reviewed.

Data availability statement No data are available.

Open access This is an open access article distributed in accordance with the Creative Commons Attribution Non Commercial (CC BY-NC 4.0) license, which permits others to distribute, remix, adapt, build upon this work non-commercially, and license their derivative works on different terms, provided the original work is properly cited, appropriate credit is given, any changes made indicated, and the use is non-commercial. See: http://creativecommons.org/licenses/by-nc/4.0/. 
ORCID iD

Shasha Yuan http://orcid.org/0000-0002-5091-6688

\section{REFERENCES}

1. Macinko J, Starfield B, Shi L. The contribution of primary care systems to health outcomes within organization for economic cooperation and development (OECD) countries, 1970-1998. Health Serv Res 2003;38:831-65.

2. Startfield B, Shi L, Macinko J. Contribution of primary care to health systems and health. Milbank Q 2005;83:457-502.

3. Kidd M. The Contribution of Family Medicine to Improving Health Systems: A guidebook from the World Organization of Family Doctors. 2nd edn. London, UK: Radcliffe Publishing, 2013.

4. Huang J, Liu S, He R, et al. Factors associated with residents' contract behavior with family doctors in community health service centers: A longitudinal survey from China. PLoS One 2018;13:e0208200.

5. Velasco Garrido M, Zentner A, Busse R. The effects of gatekeeping: a systematic review of the literature. Scand J Prim Health Care 2011;29:28-38

6. State Council. State Council's Guiding Opinion on Establishing the General Practitioner System [in Chinese], 2011. Available: http:// www.moh.gov.cn/mohrss/s7744/201107/52368.shtml [Accessed 16 Aug 2019].

7. Shao S, Wu T, Guo A, et al. The training contents, problems and needs of doctors in urban community health service institutions in China. BMC Fam Pract 2018;19:1-9.

8. Zhao Y, Chen R, Wang B, et al. General practice On-the-Job training in Chinese urban community. Plos One 2014;9:e94301.

9. Wang HHX, Wang JJ, Zhou ZH, et al. General practice education and training in southern China: recent development and ongoing challenges under the health care reform. Malaysian Family Physician 2013;8:1-9.

10. National Health Commission. Policy interpretation of syllabus for on job training program (2019 version). Available: http://www.nhc.gov. cn/qjjys/s7937/201904/af2a67d86e8749a7b53ddfdde6f563e3.shtml [Accessed 16 Aug 2019].

11. Li X, Lu J, Hu S, et al. The primary health-care system in China. Lancet 2017;390:2584-94.

12. Tang S, Meng $Q$, Chen L, et al. Tackling the challenges to health equity in China. Lancet 2008;372:1493-501.

13. Meng Q, Yuan J, Jing L, et al. Mobility of primary health care workers in China. Hum Resour Health 2009;7.

14. $\mathrm{Xu} \mathrm{H}, \mathrm{Cao} Z$, Wu S. Content analysis of China's policies for the delivery of contmcted family doctor services. Chinese General Practice 2018;21:2647-54.

15. Zhang D, Liu Y, Du J. Family doctor service evaluation by Beijing urban contract-signing residents: a qualitative study. Chinese General Practice 2017;20:1554-7.

16. Lu W, Zhang Y, Liang $\mathrm{H}$, et al. The performance evaluation based on the demand side of the family doctor contract service: a focus on chronic diseases. Chinese Journal of Health Policy 2016;9:23-30.

17. Lu W, Zhang Y, Liang $\mathrm{H}$, et al. The theoretical basis and policy value analysis for the linkage reform between the family doctor service contract and Medicare payment. Chinese Journal of Health Policy 2016:9:3-9.

18. Zhang $Y$, Zhang $T$, Wang Z. Status of signing on family doctor service for residents in Desheng area of Beijing and its influencing factors. Chinese General Practice 2013;16:3715-8.

19. Sun $H$, Chen $P$, Huang $D$, et al. The status and countermeasures of family doctors' signing service. Health Economic Review 2018;379:50-3

20. Jing $L$, Shu Z, Sun $X$, et al. Factors influencing patients' contract choice with general practitioners in Shanghai: a preliminary study. Asia Pac J Public Health 2015;27:77S-85.

21. O'Brien BC, Harris IB, Beckman TJ, et al. Standards for reporting qualitative research: a synthesis of recommendations. Acad Med 2014;89:1245-51.

22. Green J, Thorogood N. Qualitative methods for health research. Sage Publications Ltd, 2013.

23. Damschroder LJ, Aron DC, Keith RE, et al. Fostering implementation of health services research findings into practice: a consolidated framework for advancing implementation science. Implement Sci 2009;4:1-15.

24. Kegler MC, Beasley DD, Liang S, et al. Using the consolidated framework for implementation research to understand safety net health system efforts to increase colorectal cancer screening rates. Health Educ Res 2018;33:315-26.

25. Keith RE, Crosson JC, O'Malley AS, et al. Using the consolidated framework for implementation research (CFIR) to produce actionable findings: a rapid-cycle evaluation approach to improving implementation. Implement Sci 2017;12:1-12.

26. Liu L. Promoting contracted services of family doctors to strengthen the construction of hierarchical medical system. Chinese General Practice 2018;21:1-4.

27. Xu J, Mills A. Challenges for gatekeeping: a qualitative systems analysis of a pilot in rural China. Int J Equity Health 2017;16:1-21.

28. Zou Y, Zhang X, Hao Y, et al. General practitioners versus other physicians in the quality of primary care: a cross-sectional study in Guangdong Province, China. BMC Fam Pract 2015;16.

29. Irving $\mathrm{G}$, Neves $\mathrm{AL}$, Dambha-Miller $\mathrm{H}$, et al. International variations in primary care physician consultation time: a systematic review of 67 countries. BMJ Open 2017;7:e017902.

30. National Health Commission,. The statistics yearbook of national health. Beijing: China Union Medical University Press, 2018.

31. Wang F, Liu L. Theory and practice in family doctor contracting service. Beijing: Science Press, 2018.

32. Wu N, Cheng M, Yang L, et al. Training development report of GPs. Chinese General Practice 2018;21:1135-42.

33. Wang $\mathrm{G}$. The rise of general practitioners in 19th-Century Britain and its influence. World History 2016;4:91-104.

34. Jiang L. Research on health care system of Australia. Wuhan: Wuhan University of Science and Technology, 2009.

35. Li L, Zhang Z, Wang C. Enlightenment of health care security system in German to China. Chinese Hospital Management 2016;36:94-6.

36. Kontopantelis E, Springate D, Reeves D, et al. Withdrawing performance indicators: retrospective analysis of general practice performance under UK quality and outcomes framework. BMJ 2014;348:g330-17. 